\title{
Is ADD a gift or a curse?
}

Abbreviations: ADD, attention deficit disorder; ADHD, attention deficit hyperactivity disorder

\section{Editorial}

Attention Deficit Disorder (also known as ADD) and Attention Deficit Hyperactivity Disorder (ADHD) are terms used to describe patterns of behavior that appear most often in school-aged children. Children with these disorders are inattentive, overly impulsive and, in the case of ADHD, hyperactive. They have difficulty sitting still or attending to one thing for a long period of time, and may seem overactive. Up to 10 percent of children in the USA were described as having ADHD. Current estimates suggest that ADHD is present throughout the world in about 10 percent of children in the USA were described as having ADHD. Current estimates suggest that ADHD is present throughout the world in about 5 percent of the population. About five times more boys than girls are diagnosed with ADHD. Medications include two classes of drugs, stimulants and nonstimulants. Drugs for ADHD are divided into first-line medications and second-line medications.

\section{Typical Symptoms of ADD/ADD}

i. Often does not give close attention to details or makes careless mistakes in schoolwork, work, or other activities.

ii. Often has trouble keeping attention on tasks or play activities.

iii. Often does not seem to listen when spoken to directly.

iv. Often does not follow instructions and fails to finish schoolwork, chores, or duties in the workplace (not due to oppositional behavior or failure to understand instructions).

v. Often have trouble organizing activities.

vi. Often avoids, dislikes, or doesn't want to do things that take a lot of mental effort for a long period (such as schoolwork or homework).

vii. Often loses things needed for tasks and activities (e.g. Toys, School assignments, Pencils, Books or Tools).

viii. Is often easily distracted.

ix. Is often forgetful in daily activities.

\section{Recommendations}

Parents are recommended to learn about this disorder in order to first be able to help themselves and then their children. Behavioral strategies are of great help and they include creating routines, getting organized, avoiding distractions, limiting choices, using goals and rewards, ignoring behaviors. Children with ADHD can be extremely disorganized. Parents should work with them to find specific places for everything and teach kids to use calendars and schedules. Parents are advised to get children into sports to help them build discipline, confidence, and improve their social skills. Physical activity boosts the brain dopamine, norepinephrine, and serotonin levels and all these neurotransmitters affect focus and attention. Some sports may be too
Volume I Issue I - 2014

\section{George Grant \\ World organization of Natural Medicine, Richmond Hill, Canada}

Correspondence: George Grant, World organization of Natural Medicine, Richmond Hill, Ontario, Canada, Tel 416562 3|40, Emaildrgrantwellness@gmail.com

Received: November 05, 2014 | Published: November 18, 2014

challenging and would add frustration. Parents should talk with their children about what activities and exercises most stimulate and satisfy them before signing them up for classes or sports. It is important to establish close communication with the school in order to develop an educational plan to address the child needs. Accommodations in school, such as extended time for tests or more frequent feedback from teachers, are beneficial for these individuals.

When people speak about ADD because there is a natural tendency to focus on what goes wrong, or at least on what has to be somehow controlled. But often once the ADD has been diagnosed, and the child or the adult, with the help of teachers and parents or spouses, friends, and colleagues, has learned how to cope with it, an untapped realm of the brain swims into view.

Often these people are highly imaginative and intuitive. They have a feel for things, a way of seeing right into the heart of matters while others have to reason their way along methodically. This is the person who cannot explain how he thought of the solution, or where the idea for the story came from, or why suddenly he produced such a painting, or how he knew the short cut to the answer, but all he can say is he just knew it, he could feel it. This is the man or woman who makes million dollar deals in a catnap and pulls them off the next day. This is the child who, having been reprimanded for blurting something out, is then praised for having blurted out something brilliant. These are the people who learn and know and do and go by touch and feel.

In our best seller book the all in one Guide to ADD \& ADHD we indicated that this syndrome should be considered a gift rather than a curse. We recommend natural approach using proper nutrition, exercise, biofeedback instead of depending on medications.

\section{Acknowledgements}

None.

\section{Conflict of interest}

The author declares no conflict of interest. 